\title{
RESEARCH RESOULTS OF GRAIN SHREDDER BY USING MULTIPLIED METHOD OF EVALUATION ${ }^{1}$
}

Petr A. Savinykh ${ }^{a^{*}}$, Alexey Yu. Isupov ${ }^{\mathrm{a}}$, Andrey Palichyn ${ }^{\mathrm{b}}$, Ilaya I. Ivanov ${ }^{\mathrm{b}}$, Wacław Romaniuk ${ }^{\mathrm{c}}$, Kinga Borek ${ }^{\mathrm{c}}$

a GNU NIISH-SH North-East Scientific and Research Institute of Agriculture N.V. Rudnitshy, Kirov, Russia

b FGBOU Vologckaya GMHA NV. Vereshagina, Vologda, Russia

c Institute of Technology and Life Sciences in Falenty, Warsaw Branch, Poland

${ }^{*}$ Corresponding author: e-mail: peter.savinyh@mail.ru

\begin{tabular}{|c|c|}
\hline ARTICLE INFO & ABSTRACT \\
\hline $\begin{array}{l}\text { Article history: } \\
\text { Received: November } 2018 \\
\text { Received in the revised form: } \\
\text { December } 2018 \\
\text { Accepted: January } 2019 \\
\end{array}$ & \multirow{2}{*}{$\begin{array}{l}\text { Currently in Russia and other countries in family farms there is } \\
\text { a demand for lowering cost of animal production. Main direction to } \\
\text { achieve new terchnological solutions characterized by low energy } \\
\text { constumption and high efficiency with maintaining high quality of } \\
\text { product (mineral). For example, lately in animal production are ac- } \\
\text { quired concentrates with low unity costs. Realising targets releated } \\
\text { with lowering costs of forage production with usage comminution and } \\
\text { crease of grain. Previously conducted own researches and literature } \\
\text { analises shows, that currently used solutions are characterized by big } \\
\text { errors made by construction of the devices, and technology effect of } \\
\text { obtained product (grain). The paper presents the criteria for optimali- } \\
\text { zation of technical indicators of shredding devices affecting the quali- } \\
\text { ty of the product. }\end{array}$} \\
\hline $\begin{array}{l}\text { Key words: } \\
\text { shredding devices, } \\
\text { grain, } \\
\text { experiment, } \\
\text { rotor, } \\
\text { shredding unit }\end{array}$ & \\
\hline
\end{tabular}

\section{Постановка проблемы}

Толчком для разработки и внедрения современных энергосберегающих технологий в сельскохозяйственном производстве, послужила политика импортозамещения и государственной поддержки отечественного производителя сельскохозяйственной продукции.

Половина всего производимого в мире зерна используется для кормления сельскохозяйственных животных. Основным направлением применения этого зернового материала является производство комбинированных кормов, так в их состав может входить от 30 до $80 \%$ злаковых и бобовых культур, а также продуктов их переработки. Использование в составе комбикормов концентрованных кормов в

1 Исследования, выполненные в рамках проекта "Междисциплинарные исследования по повышению энергоэффективности и увеличению доли возобновляемых источников энергии в энергетическом балансе польского сельского хозяйства", Номер контракта ВIOSTRATEG1/269056/5/NCBR/2015 11.08.2015 год, финансируемый по Национальный Центр Исследований и Разработок в рамках программы BIOSTRATEG1. 
Petr A. Savinykh et al.

отличие от зерна, не подвергаемому никакому механическому или термическому воздействию, повышает их эффективность до 10-20\% (Siergejev, 2008).

В структуре себестоимости продукции животноводства более 50\% занимают затраты на производство кормов. При этом всего не более четверти использованной энергии корма возвращается в виде молока, мяса, шерсти и т.д. Оставшаяся доля расходуется на поддержание физиологической активности животного - дыхание, кровообращение, переваривание пищи и т.д. (Solitsev, 2008). Поэтому снижение всех затрат связанных с производством кормов; повышение качества кормов за счет улучшения перевариваемости и усвояемости являются важнейшими задачами науки и техники в области сельского хозяйства.

В сфере агропромышленного производства и в частности механизации животноводства основными направлениями решения описанной проблемы являются технические средства оптимизации конструктивных элементов уже известных устройств с подбором технологических режимов, а также разработка и внедрение новых технических решений. Например, в настоящее время, большой практический интерес в области измельчения зерна, представляют конструкции измельчителей, работающие в пограничной области, то есть совмещающие процесс измельчения срезом и скалыванием (Sysujev и др., 2008; Suhlaev и др., 2014; Bulatov и др., 2014).

\section{Анализ последних исследований.}

В настоящее время разработано и используется огромное количество всевозможных конструкций дробилок кормов, которые отличаются между собой принципом работы и технологической схемой. Тем не менее все это разнообразие делят на решетные, универсальные и безрешётные дробилки, а также с рециркуляции и без нее.

В последние годы за рубежом (США, Западная Европа) вновь вернулись к использованию дезинтеграторов и других машин ударного действия для измельчения пищевых продуктов. Опыты применения машин ударного действия с целью интенсификации измельчения и сокращения протяженности размольного процесса ведутся во многих странах. Необходимо отметить, что ударное измельчение стремятся применять в сочетании с пневматическим сепарированием. Для этих целей используются молотковые дробилки разных типов, дезинтеграторы (штифтовые дробилки), роторные дробилки, машины центробежного типа, в которых измельчение осуществляется путем удара продукта о неподвижную кольцевую поверхность или деку с ребристой или ровной поверхностью, и многие другие.

Основными преимуществами дисковой дробилки являются: возможность измельчения различного по крупности зерна, обеспечение хорошего качества размола при малом содержании мелкой фракции, возможность регулирования рабочего зазора в процессе работы. К основным недостаткам следует отнести быстрый износ рабочих поверхностей и большой удельный расход энергии. Дисковые дробилки не нашли применения в комбикормовой промышленности нашей страны, и отечественным машиностроением не выпускаются.

В комбикормовой промышленности и сельскохозяйственном производстве для измельчения зернового сырья в основном используются молотковые и вальцовые 
Research resoults...

станки, в отдельных случаях - дисковые дробилки и жернова. Наиболее распространены как универсальные, так и специализированные молотковые дробилки, например, КДМ-3,0, КДУ-2,0 и др. (Sysujev и др., 2008)

Доказано, что в зависимости от конструктивных особенностей дробилок окружная скорость молотков 45-70 м.с ${ }^{-1}$ обеспечивает разрушение зерна за счет первичного удара. На зарубежных комбикормовых предприятиях процесс измельчения зернового сырья ведется при окружных скоростях молотков в пределах 80-115 м. $\mathrm{c}^{-1}$. В настоящее время отечественная комбикормовая промышленность использует молотковые дробилки, у которых окружная скорость молотков 90-100 м·с ${ }^{1}$.Имеющиеся отклонения в рассмотренных параметрах работы молотковых дробилок объясняются различными задачами, которые ставились при выполнении исследований, а также отсутствием единого метода оценки технологического процесса измельчения. 2008):

К существенным недостаткам молотковых дробилок следует отнести (Siergejev,

- высокий удельный расход энергии на измельчение (до $54 \cdot 10^{3}$ кДж· $\mathrm{T}^{-1}$ );

- большое количество тонкодисперсной фракции в продуктах дробления (при среднем и мелком размоле до $30 \%$ );

- быстрый износ рабочих органов;

- относительно высокую металлоемкость (до 500 кг·ч· $\mathrm{T}^{-1}$ ).

К существенным недостаткам центробежных дробилок следует отнести следующее: снижается качество измельченного продукта при увеличении подачи материала в камеру дробления для повышения производительности, при этом увеличивается выход целых и неизмельчённых частиц исходного материала; не представляется возможным измельчать зерно повышенной влажности (17-20\%), а также семена масличных культур, например, рапса.

Многообразие машин, применяемых для измельчения, свидетельствует о том, что до настоящего времени продолжаются поиски наиболее рационального типа измельчающей машины, которая наряду с высокой технологической эффективностью, обеспечила бы большую производительность и меньший расход энергии по сравнению с существующими.

Поэтому целью исследования являлась оценка влияния ряда конструктивных и кинематических параметров, выявленных в ходе анализа, предложенной конструкции измельчителя роторно-центробежного типа на качество получаемого продукта измельченного зерна и на его выходные технологические характеристики. Основными задачами нашего исследования явились: установление и оценка влияния и взаимосвязей конструктивных и кинематических параметров на технологические показатели работы измельчителя, а также соответствие получаемого продукта зоотехническим требованиям, выбор дальнейшего направления исследований, предложенной нами, конструкции измельчителя зерна роторно-центробежного типа.

\section{Результаты исследований}

Установление влияния различных факторов на процесс измельчения зерна, выходные энергетические и технологические параметры в устройстве для 
Petr A. Savinykh et al.

измельчения зерна роторно-центробежного типа проводилось на экспериментальной установке (Рис. 1). Исследования проводились на материально-технической базе ФГБОУ ВО Вологодская ГМХА имени Н.В. Верещагина.

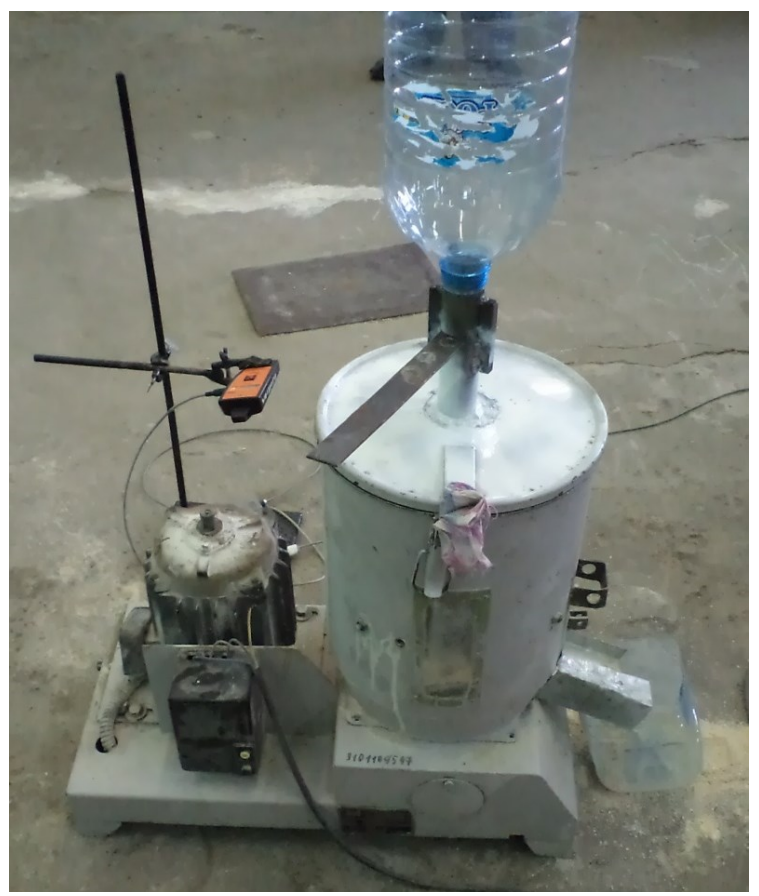

Рисунок 1. Общчий вид экспериментальной установки

При этом устройство для измельчения зерна роторно-центробежного типа (Рис. 2) состоит из неподвижного корпуса 1 с загрузочным 2 и выходным 3 патрубками. Внутри корпуса соосно установлены два вращающихся смежных диска: верхний 4 (Рис. 3) и нижний 5 (Рис. 4). На рабочей поверхности нижнего диска 5 выполнены кольцевые выступы 6, а на рабочей поверхности верхнего диска 4 установлены ножи 7, которые выполнены в виде ромба с малыми углами заточки относительно больших диагоналей, причем наружный ряд ножей 8 образует сепарирующую поверхность, изменение угла наклона которых позволяет бесступенчато регулировать степень измельчения материала. Нижний диск 5 имеет в радиальном направлении сквозные пазы 9, выполненные под наклоном в сторону противоположную направлению вращения данного диска. Нижний диск 5 укреплен на фланце приводного вала 10 и приводятся во вращение посредством установленного на нем шкива 11. Верхний диск 4 жестко закреплен к неподвижному корпусу 1. В верхней части неподвижного корпуса установлена приемная камера 12, которая образована вертикальными стенками. Приемная камера 12 в верхней части сообщена с загрузочным патрубком 2 
Research resoults...

и посредством радиальных окон 13 связана с рабочей камерой 14, представляющей собой пространство между дисками 4 и 5.

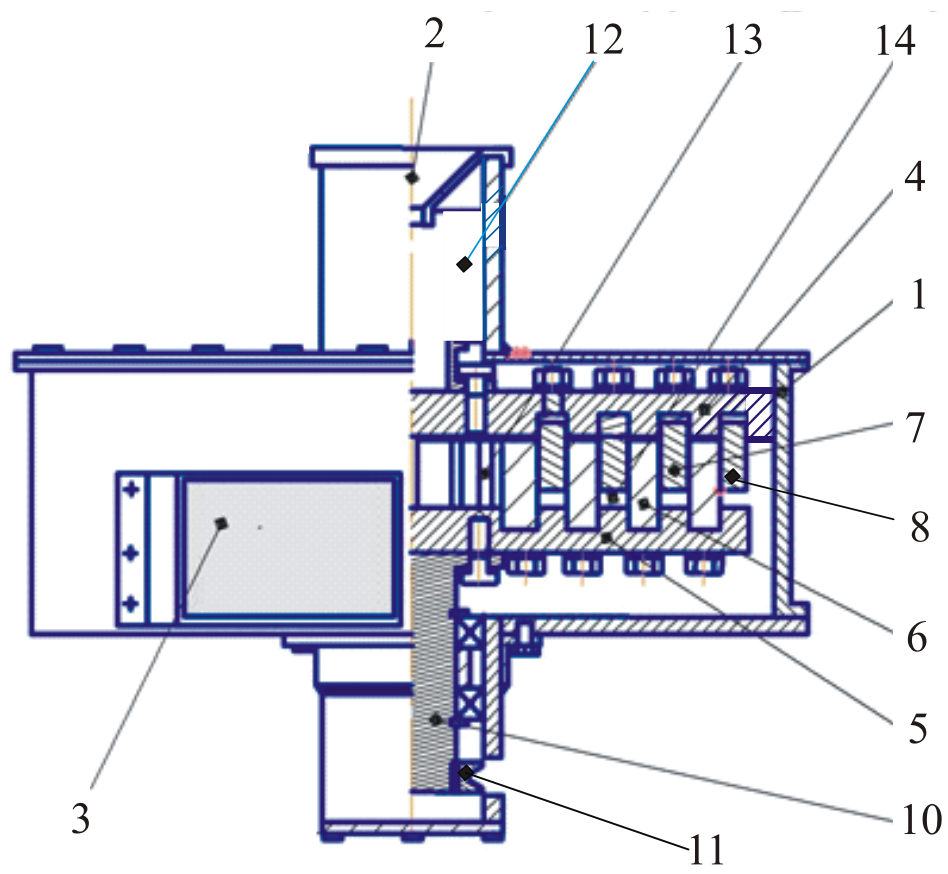

Рисунок 2. Общий вид устройства для измельчения сыпучих материалов

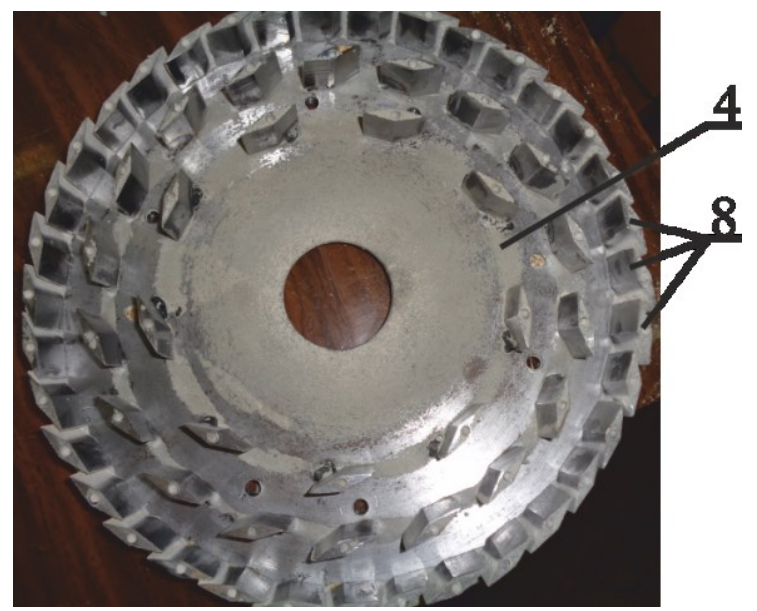

Рисунок 3. Общций вид верхнего диска 
Petr A. Savinykh et al.

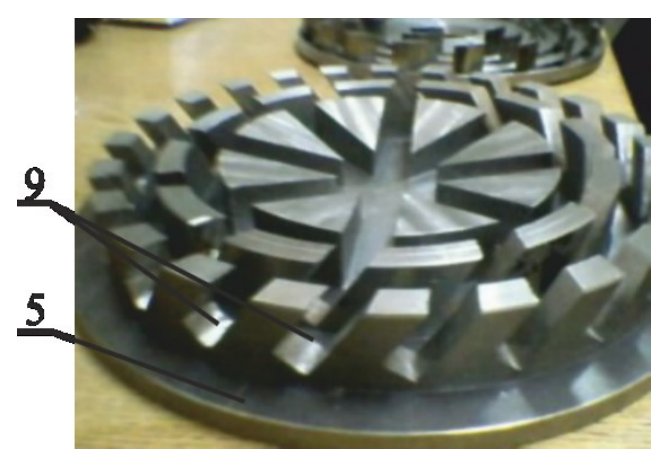

Рисунок 4. Общий вид нижнего диска

Рабочий процесс измельчения зерна в устройстве роторно-центробежного типа осуществлялся следующим образом. Поступающее зерно, подвергается механическому воздействию первой режущей пары, далее под действием центробежных сил предварительно измельченный материал двигается по сквозным пазам к следующей паре. А далее измельченное зерно - дерть, достигнув наружного ряда ножей 8, которые образуют сепарирующую поверхность, проходит в зазор между ножами 8 и под воздействием воздушного потока, создаваемого вращающимся нижним диском 5, выходит из корпуса 1 через выходной патрубок 3 .

Для решения поставленных задач по исследованию влияния конструктивных и кинематических параметров измельчителя зерна роторно-центробежного типа на выходные технологические и качественные показатели использована методика планирования многофакторного эксперимента (Mielnikov и др., 1980; Montgomeri, 1980; Dzhonson, Likon, 1981).

Анализ конструкции измельчителя и исследований по этой тематике позволил выделить ряд факторов. Которые условно можно поделить на конструктивные, например, количество ножей на внутреннем и наружном кольце, и технологические факторы, например, подача зерна и частота вращения ротора. Выбранные по результатам однофакторных экспериментов факторы и уровни их варьирования (Табл. 1)

Таблица 1.

Факторы и уровни их варьирования

\begin{tabular}{|c|c|c|c|}
\hline \multirow{2}{*}{ Факторы } & \multirow{2}{*}{ Наименование и размерность } & \multicolumn{2}{|c|}{ Уровни факторов } \\
\hline & & $-1,0$ & $+1,0$ \\
\hline$\overline{x_{1}}$ & Подача зерна, герц. & 30 & 60 \\
\hline$x_{2}$ & Частота вращения ротора, $\mathrm{c}^{-1}$ & 800 & 1200 \\
\hline$x_{3}$ & Открытие сепарирующей поверхности, мм. & 2,5 & 3,2 \\
\hline$x_{4}$ & Число ножей на внутреннем кольце, шт. & 9 & 3 \\
\hline$x_{5}$ & Число ножей на наружном кольце, шт. & 18 & 9 \\
\hline$x_{6}$ & Состояние ножей & старые & Новые \\
\hline$x_{7}$ & Наличие вставки & есть & Нет \\
\hline
\end{tabular}


Research resoults...

В ходе проведения исследования в качестве исходного зернового материала использовался ячмень кондиционной влажности. Регулировка подачи зерна в устройство $x_{1}$ осуществлялась за счет изменения частоты вращения вала электродвигателя лопастного питателя. Частота вращения ротора $x_{2}$ регулировалась за счет изменения передаточного отношения ременной передачи между шкивом электродвигателя и шкивом приводного вала измельчителя 10 (Рис. 2). Открытие сепарирующей поверхности $x_{3}$ - за счет выставления соответствующего размера между параллейными плоскостями двух рядом расположенных ножей на внешнем кольце 8 (Рис. 3). Число ножей на внутреннем $x_{4}$ и наружном кольце $x_{5}-$ в результате добавления или удаления таковых. В качестве фактора $x_{6}$ использовались новые заточенные ножи и старые - потерявшие заточку.

Для сокращения объема, проводимых исследований использовалась матрица дробного факторного эксперимента типа $2^{7-2}$. Матрица планирования и результаты эксперимента представлены в табл. 2.

За критерии оптимизации, оценивающие выходные конструкционнотехнологические показатели работы измельчителя зерна, принимались: потребляемая мощность $y_{1}$, в кВт, и производительность измельчителя $y_{2}$, выражаемая в кг·с ${ }^{-1}$. Замер показателей потребляемой мощности осуществлялся при помощи счетчика электрической энергии Меркурий 221, подключенного к ПК через интерфейс USB в CAN/RS-232/RS485 (Рис. 5). Блок схема замера потребляемой мощности). Мгновенный контроль показателей отслеживался измерительным комплектом К-505.

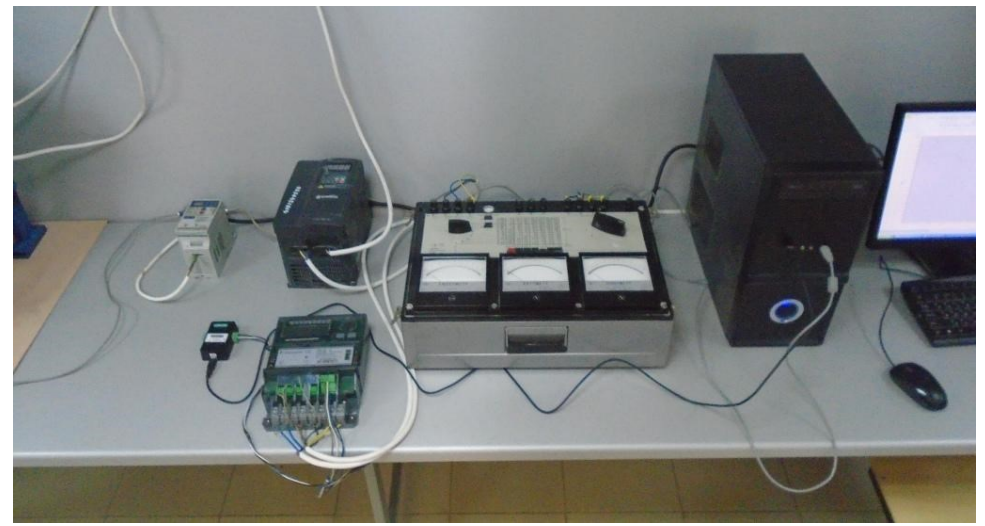

Рисунок 5. Комплект измерительного оборудования при проведении исследований

Производительность экспериментальной установки рассчитывалась по формуле:

$$
y_{2}=\frac{M,}{t}
$$

где:

M - масса навески зерна, (кг)

$\mathrm{t} \quad$ - время истечения навески из бункера, (сек) 
Petr A. Savinykh et al.

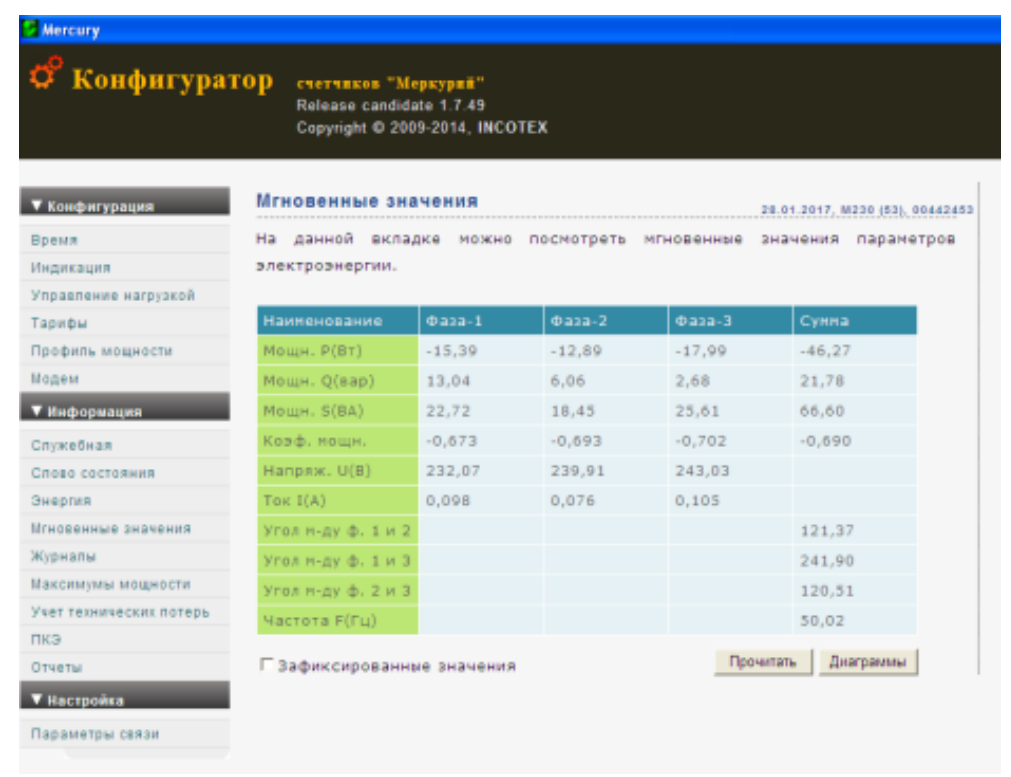

Рисунок 6. Фрагмент записи расхода мощчности на ваттметре-самописие

Таблица 2.

Матрица планирования эксперимента и результаты исследований

\begin{tabular}{crrrrrrrrccc}
\hline \multirow{2}{*}{$o$} \\
п/п & \multicolumn{1}{c}{ Факторы } & $x_{1}$ & $x_{2}$ & $x_{3}$ & $x_{4}$ & $x_{5}$ & $x_{6}$ & $x_{7}$ & $y_{1}$ & $y_{2}$ & $y_{3}$ \\
\hline 1 & 1 & 1 & 1 & -1 & -1 & -1 & 1 & 5,28 & 0,029 & 0,68 \\
2 & 1 & -1 & 1 & -1 & -1 & 1 & -1 & 2,28 & 0,015 & 2,19 \\
3 & 1 & 1 & -1 & -1 & 1 & 1 & -1 & 3,12 & 0,033 & 38,19 \\
4 & 1 & 1 & 1 & -1 & 1 & -1 & -1 & 6,54 & 0,024 & 2,59 \\
5 & 1 & -1 & 1 & 1 & -1 & -1 & 1 & 4,44 & 0,017 & 6,88 \\
6 & 1 & -1 & -1 & -1 & -1 & -1 & -1 & 4,68 & 0,023 & 0,30 \\
7 & 1 & 1 & 1 & 1 & -1 & 1 & -1 & 2,46 & 0,034 & 5,27 \\
8 & 1 & 1 & 1 & 1 & 1 & 1 & 1 & 3,12 & 0,032 & 14,61 \\
9 & 1 & -1 & 1 & 1 & 1 & -1 & -1 & 6,36 & 0,011 & 24,29 \\
10 & 1 & -1 & -1 & -1 & 1 & -1 & 1 & 5,22 & 0,025 & 0,77 \\
11 & 1 & 1 & -1 & -1 & -1 & 1 & 1 & 2,58 & 0,029 & 9,76 \\
12 & 1 & -1 & -1 & 1 & -1 & 1 & 1 & 2,82 & 0,022 & 0,96 \\
13 & 1 & 1 & -1 & 1 & -1 & -1 & -1 & 4,2 & 0,030 & 60,66 \\
14 & 1 & -1 & -1 & 1 & 1 & 1 & -1 & 2,1 & 0,026 & 7,95 \\
15 & 1 & 1 & -1 & 1 & 1 & -1 & 1 & 6,42 & 0,027 & 20,54 \\
16 & 1 & -1 & 1 & -1 & 1 & 1 & 1 & 2,64 & 0,022 & 0,49 \\
17 & -1 & 1 & -1 & -1 & -1 & -1 & -1 & 5,34 & 0,016 & 1,01
\end{tabular}


Research resoults...

\begin{tabular}{ccrrrrrrrcc}
\hline \multirow{2}{*}{$№$} \\
\cline { 2 - 9 } п/п & $x_{1}$ & $x_{2}$ & $x_{3}$ & $x_{4}$ & $x_{5}$ & $x_{6}$ & $x_{7}$ & $y_{1}$ & $y_{2}$ & Критерии оптимизации \\
\hline 19 & -1 & -1 & 1 & -1 & -1 & -1 & 1 & 3,66 & 0,017 & 1,33 \\
20 & -1 & 1 & 1 & -1 & 1 & 1 & 1 & 2,34 & 0,021 & 6,22 \\
21 & -1 & -1 & -1 & 1 & 1 & -1 & 1 & 6,54 & 0,012 & 1,22 \\
22 & -1 & -1 & -1 & -1 & -1 & 1 & 1 & 2,28 & 0,019 & 28,61 \\
23 & -1 & 1 & 1 & -1 & -1 & 1 & -1 & 3,06 & 0,018 & 0,40 \\
24 & -1 & -1 & -1 & -1 & 1 & 1 & -1 & 2,58 & 0,020 & 46,84 \\
25 & -1 & -1 & 1 & -1 & 1 & -1 & -1 & 3,72 & 0,012 & 11,39 \\
26 & -1 & -1 & 1 & 1 & -1 & 1 & -1 & 1,92 & 0,019 & 3,60 \\
27 & -1 & -1 & 1 & 1 & 1 & 1 & 1 & 2,52 & 0,014 & 12,70 \\
28 & -1 & 1 & -1 & -1 & 1 & -1 & 1 & 6,54 & 0,014 & 0,49 \\
29 & -1 & 1 & -1 & 1 & 1 & 1 & -1 & 2,94 & 0,019 & 1,66 \\
30 & -1 & 1 & 1 & 1 & -1 & -1 & 1 & 5,1 & 0,017 & 5,22 \\
31 & -1 & 1 & 1 & 1 & 1 & -1 & -1 & 4,44 & 0,016 & 13,18 \\
32 & -1 & 1 & -1 & 1 & -1 & 1 & 1 & 2,04 & 0,021 & \\
\hline
\end{tabular}

Анализ зоотехнических требований, предъявляемых к концентрированным кормам для различных групп животных, позволил выделить несколько основных критериев для оценки качества получаемого продукта. Это крупность помола, процентное содержанию в помоле частиц более 3 мм и наличие в помоле целых зерен. Однако результаты рассева на вибросите отобранных проб показали, что наиболее критичным параметром для получаемого продукта является содержание в помоле частиц более 3 мм $y_{3}$. При этом наличие целых зерен и модуль помола не рассматривались в виду того что, в рассеве не наблюдалось целых зерен, а значение модуля соответствовало грубому помолу. При этом стоит отметить, что модуль помола в большой степени зависел от содержания частиц более 3 мм, так, например, их содержание варьировалось в диапазоне от 0,4 до $60,8 \%$.

Результаты (табл. 3) многофакторного дисперсионного анализа ANOVA данных, представленных в таблице 2, и полученных при этом уравнений регрессии (1), (2) и (3), позволили сделать вывод, что коэффициенты уравнений адекватны; математические модели (1), (2) и (3), обусловлены вариацией выбранных факторов (табл. 1), являются статистически значимыми и не могут описать происходящие процессы лишь на 5\% уровне.

Таблица 3.

Результаты дисперсионного анализа моделей (ANOVA)

\begin{tabular}{lccc}
\hline Наименование & $y_{1}$ & $y_{2}$ & $y_{3}$ \\
\hline Вероятность ошибки при отклонении нулевой гипотезы (P-value) & 0,0000 & 0,0000 & 0,0000 \\
Число исключенных значений (Error d.f.) & 20 & 18 & 20 \\
Стандартная ошибка оценивания (Stnd. Error) & 0,464976 & 0,001784 & 4,21375 \\
Коэффициент детерминации (R-squared) & 94,26 & 95,64 & 95,89 \\
\hline
\end{tabular}


Petr A. Savinykh et al.

$$
\begin{gathered}
y_{1}=3,89+0,122 * x_{1}+0,201 * x_{2}-0,152 * x_{3}+0,302 * x_{5}-1,34 * x_{6}+0,276 * x_{1} * x_{3}+ \\
0,122 * x_{1} * x_{5}-0,283 * x_{2} * x_{4}+0,144 * x_{3} * x_{6}-0,182 * x_{3} * x_{7}-+0,126 * x_{4} * x_{7} \\
y_{2}=0,0208+0,00409 * x_{1}+0,00291 * x_{2}-0,000969 * x_{3}+0,00191 * x_{6}+0,00191 * x_{1} * x_{2}- \\
0,000969 * x_{1} * x_{3}+0,00109 * x_{2} * x_{3}+0,000969 * x_{2} * x_{4}-0,000531 * x_{3} * x_{5}+0,000969 * x_{3} * x_{7}- \\
0,000656 * x_{4} * x_{5}+0,000844 * x_{4} * x_{6}-0,000656 * x_{4} * x_{7} \\
y_{3}=13,1+1,71 * x_{1}-3,38 * x_{2}-5,6 * x_{3}+2,4 * x_{4}+5,75 * x_{5}+8,88 * x_{6}-2,6 * x_{7}+3,01 * x_{1} * x_{4}- \\
1,68 * x_{2} * x_{6}-8,16 * x_{3} * x_{6}+3,2 * x_{3} * x_{7}
\end{gathered}
$$

Проведенный анализ моделей регрессии потребления электроэнергии (1) и производительности (2), а также содержания в готовом продукте частиц более 3 мм (3) выявил что:

1. Подача зерна $x_{I}$ является главным фактором, оказывающим влияние на производительность измельчителя $y_{2}$, однако изменение подачи $x_{1}$ в выбранном диапазоне варьирования не оказывает столь значительного влияния на энергопотребление $y_{1}$ и содержание в помоле $y_{3}$ частиц более 3 мм, что может говорить о не полной нагрузке измельчителя;

2. Увеличение частоты вращения нижнего диска $x_{2}$ оказывает положительное влияние на качество готового продукта $y_{3}$ и рост производительности измельчителя $y_{2}$, однако увеличивает потребляемую мощность $y_{1}$;

3. Увеличение зазора между декой с 2,5 до 3,2 мм $x_{3}$ приводит к улучшению качества получаемого продукта, за счет снижения в помоле частиц более 3 мм $y_{3}$, а также снижению пропускной способности $y_{2}$ и потребляемой электроэнергии измельчителя сыпучих материалов $y_{i}$;

4. Анализ математической модели (3), показывает, что, снижение числа ножей на внутреннем кольце $x_{4}$ позволяет также уменьшить в помоле количество частиц более 3 мм $y_{3}$. Однако изменение количества ножей на внутреннем кольце $x_{4}$ не оказывает существенного влияния на производительность $y_{2}$ и энергетические затраты $y_{l}$ измельчителя;

5. Установка на наружном кольце $x_{5}$ большего количества ножей не способствует уменьшению содержания в количества частиц более 3 мм $y_{3}$ и снижению потребляемой мощности $y_{i}$;

6. Ухудшение технического состояния ножей (износ, затупления ножей) $x_{6}$ снижает количество частиц размером более 3 мм $y_{3}$ и производительность измельчителя $y_{2}$, а также увеличивает затраты электроэнергии на измельчение сыпучих материалов $y_{l}$;

7. Фактор $x_{7}$ не оказывает, существенного влияния на потребляемую мощность $y_{1}$ и производительность измельчителя $y_{2}$. Однако ее отсутствие положительно сказывается на качестве получаемого продукта - снижению содержания в помоле частиц более 3 мм $y_{3}$.

Анализ двумерных сечений, представленных на рис. 7, показывает, что:

1. Наличие вставки $x_{7}$ с увеличением величины установки зазора сепарирующей поверхности $x_{3}$ (рис. 7,a) несколько снижает производительность измельчителя 
Research resoults...

сыпучих кормов $y_{2}$, но уменьшает содержание в помоле частиц более 3 мм. Также при отсутствии вставки $x_{7}$ и минимальном зазоре сепарирующей поверхности $x_{3}$ достигается снижение содержания в помоле частиц более 3 мм на 10-12\%;

2. Из рис. 7,6 и 7,Г следует, что увеличивая частоту вращения $x_{2}$ и уменьшая количество, установленных ножей на внутреннем диаметре $x_{4}$, возможно увеличение производительности измельчителя зерна $x_{2}$ в 1,5 раза без корректировки площади сепарирующей поверхности $x_{3}$;

3. Открытие сепарирующей поверхности $x_{3}$ при выбранных значениях подачи зерна $x_{1}$ не оказывает значительных изменений на производительность измельчителя $y_{2}$. Также на верхних уровнях варьирования подачи зерна $x_{I}$ наблюдается установившееся в 2,9 кВТ потребление электроэнергии измельчителя вне зависимости от величины открытия сепарирующей поверхности $x_{3}$, а при минимальной подаче $x_{1}$ уменьшение зазора $x_{3}$ приводит к росту потребляемой энергии $y_{1}$ до $30 \%$ (рис.7,в);

4. Из двумерного сечения (рис. 7,e) следует, что с износом ножей $x_{6}$ содержание в помоле частиц более 3 мм $y_{3}$ уменьшается вне зависимости от открытия сепарирующей поверхности $x_{3}$;

5. Из представленном на рис. 7,д графика следует, что установка меньшего количества ножей на внутреннем диаметре $x_{4}$ способствует более плавному изменению количеству потребляемой электроэнергии $y_{1}$ вне зависимости от увеличения частоты вращения $x_{2}$.

Результаты поиска оптимальных значений факторов (Табл. 5) и получаемых при этом значений критериев оптимизации (табл. 4) с помощью пакета программ StatGraphics говорит о том, что: при установке подачи зерна лопастным питателем $x_{1}-60$ Герц; при частоте вращения ротора $x_{2}-1200$ об·мин ${ }^{-1}$; при величине открытия сепарирующей поверхности $x_{3}$ в 3,2 мм; при установке на внутреннем кольце $x_{4}$ шесть, а на наружном $x_{5}$ девять ножей; при установке новых ножей $x_{6}$ и отсутствии вставки $x_{7}$ - достигается минимальная потребляемая мощность $y_{1}$ в 2,59 кВТ при максимальной производительности $y_{2}-0,032$ кг·c $\mathrm{c}^{-1}$ и полном отсутствии в помоле частиц более 3 мм $y_{3}$. При этом общее достижение результатов, по предъявленным параметрам, составила в среднем $87,8 \%$.

Таблица 4.

Оптимальные значения критериев оптимизации в пакете программ StatGraphics

\begin{tabular}{|c|c|c|c|c|c|c|c|c|}
\hline $\begin{array}{l}\text { Наименован } \\
\text { ие (Name) }\end{array}$ & $\begin{array}{c}\text { Цель (Go- } \\
\text { al) }\end{array}$ & $\begin{array}{c}\text { Чувствитель } \\
\text { ность (Sensi- } \\
\text { tivity) }\end{array}$ & $\begin{array}{c}\text { Нижн } \\
\text { ий } \\
\text { урове } \\
\text { нь } \\
\text { (Low) }\end{array}$ & $\begin{array}{c}\text { Верхн } \\
\text { ий } \\
\text { уровен } \\
\text { ь } \\
\text { (High) }\end{array}$ & $\begin{array}{c}\text { Ср. } \\
\text { прогнозиру } \\
\text { емое } \\
\text { значение } \\
\text { критерия } \\
\text { (Prediction) }\end{array}$ & $\begin{array}{c}\text { Lower } \\
95,0 \% \\
\text { Limit }\end{array}$ & $\begin{array}{c}\text { Upper } \\
95,0 \% \\
\text { Limit }\end{array}$ & $\begin{array}{c}\text { Достигнутая } \\
\text { желанность } \\
\text { (Desirability) }\end{array}$ \\
\hline$y_{l},(\kappa \mathrm{BT})$ & Minimize & Medium & - & - & 2,59 & 2,00 & 3,18 & 0,76 \\
\hline$y_{2},\left(\kappa \Gamma \cdot\right.$ сек $\left.^{-1}\right)$ & Maximize & Medium & - & - & 0,032 & 0,0303 & 0,034 & 0,86 \\
\hline$y_{3},(\%)$ & Minimize & Medium & 0,0 & 10,0 & $-0,000022$ & $-4,91$ & 4,91 & 1,0 \\
\hline
\end{tabular}


Petr A. Savinykh et al.

a)

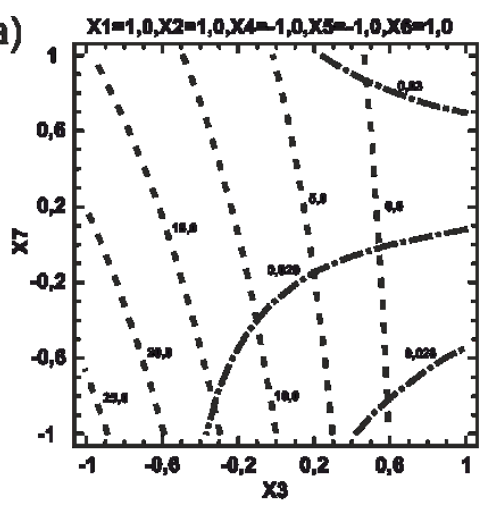

B)

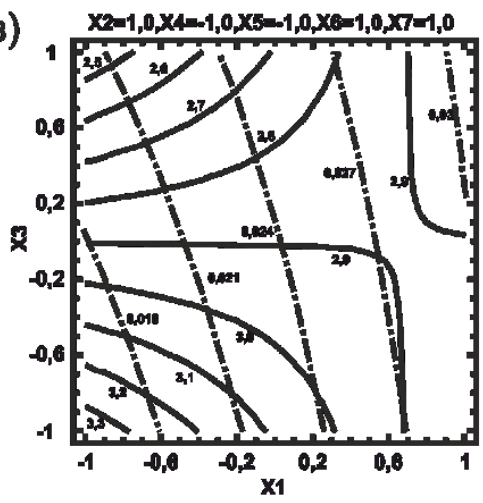

д)

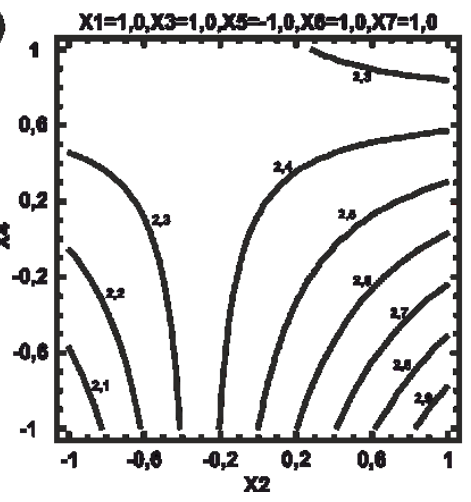

б)

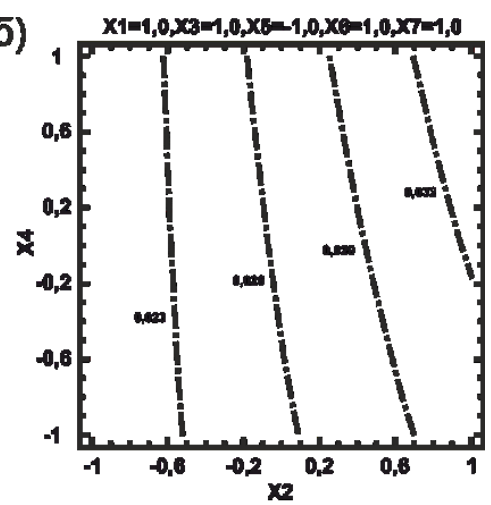

г)

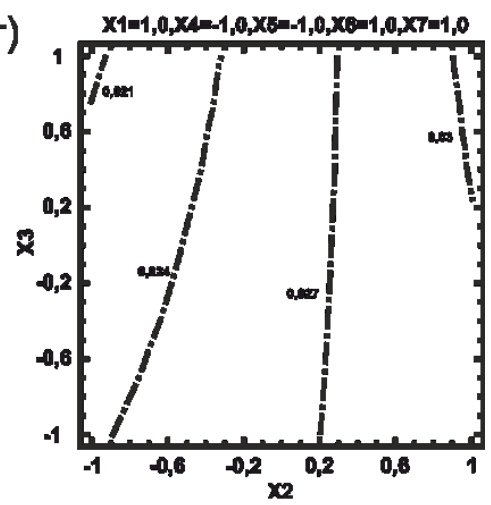

e)

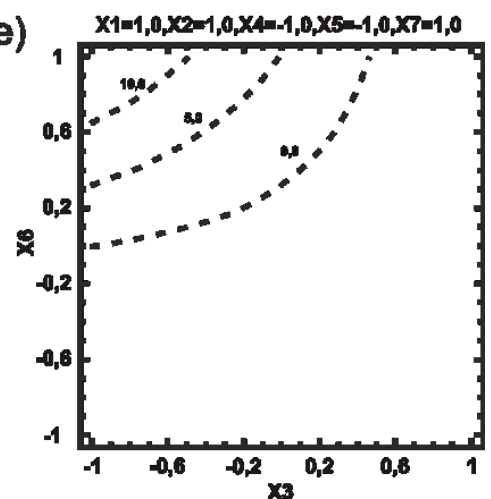

Рисунок 7. Двумерные сечения поверхностей отклика, характеризующие:

- потребляемую мошность $y_{1}$,

- производительность измельчителя у2,

- содержание в помоле частии более 3 мм уз. 
Research resoults...

Таблица 5.

Оптимальные значения факторов полученные в пакете программ StatGraphics

\begin{tabular}{llllllll}
\hline Фактор & $x_{1}$ & $x_{2}$ & $x_{3}$ & $x_{4}$ & $x_{5}$ & $x_{6}$ & $x_{7}$ \\
\hline значение & 1 & 1 & 1 & 0,057 & -1 & 1 & 1 \\
\hline
\end{tabular}

\section{Выводы}

1. Из проведенного анализа полученных данных, можно заключить, что:

- исследуемый измельчитель в выбранном диапазоне факторов недогружен; наличие вставки $x_{7}$ не оказывает положительного влияния на все критерии оптимизации;

- количество ножей на наружном ободе $x_{5}$ является более важным фактором оказывающим влияние на критерии оптимизации в отличии от ножей на внутреннем ободе $x_{4}$;

- при общем уменьшении количества ножей наблюдается рост производительности измельчителя и качества получаемого продукта, а также уменьшение потребляемой мощности;

- предварительно выбранные границы варьирования факторов позволяют получать только грубый помол;

- при увеличении величины зазора до 3,2 мм техническое состояние ножей $x_{6}$ не влияет рост содержания в помоле частиц более 3 мм.

2. По результатам проведенного исследования и поиска оптимальных значений факторов было принято решение для факторов подачи материала $x_{1}$, частоты вращения ротора $x_{2}$ и величины открытия сепарирующей поверхности $x_{3}$ расширить интервал варьирования, а от наличия вставки $x_{7}$ отказаться. При этом число ножей на внутреннем кольце $x_{4}$ ограничить -3 шт., а состояние ножей $x_{6}-$ новые; рассмотреть возможность исследования различных углов заточки ножей.

\section{Литература}

Bulatov, S.Yu., Nechaev, V.N., Savinykh, P.A. (2014). Razrabotka drobilki zierna dla kvestijanskih, hazjaystvi i rezultaty issledovanii po optimizatsii jeyo konstruktivno-tehnologicheskih parametrov. Nizhegorodtskiy gosudarstvienyi inzhinerno-ekonomicheskiy unemimut. Kniaginino.

Dzhonson, N., Likon, F. (1981). Statistika i planirovanye eksperimenta i tehniki v nauce: mietody planirovaniya eksperimenta (per s ang.), Moskva, 520.

Mielnikov, S.V., Aleshkin, V.R., Roshchin, P.M. (1980). Planirovanie eksperimenta $v$ isledovaniyah protsesov. Leningrad, Kolos, 168.

Montgomeri, D.K. (1980). Planirovanie eksperimenta i analiz danyh (per. s ang.). Leningrad, Sudostroeniye, 380 .

Siergejev, N.S. (2008). Tsentvobiezhno-rotornye iznekchiteli furazhnovo zierna. Chelabinsk, Diss, dokt, teh, nauk.

Solitsev, R.V. (2010). Tsentrabezhnyj ismielchitel zierna. Viestnik Altayskovo Agrainovo Universiteta, Vypusk, №4 (66), 76-80.

Suhlaev, V.A., Molin, A.A., Mezlyakov, I.V. (2014). Ustroytvo dla izmielcheniya sypochih materialov. Patent № 146644. Rosyjska Federatsija, MPK V02S 13/00 (20.10.2014), Bjul, № 29

Sysujev, V.A., Aleszkin, A.A., Savinykh, P.A. (2008). Kormoprigatovitielnyje mashiny. Teoria, razrabotka, eksperiment. Kirov, Zonalnyj NIISH Sieverno-Vostoka, Tom I, 640. 
Petr A. Savinykh et al.

\title{
REZULTATY BADAŃ ROZDRABNIACZA ZIARNA Z WYKORZYSTANIEM WIELOKRYTERIALNEJ METODYKI OCENY
}

\begin{abstract}
Streszczenie. Obecnie, w Rosji i innych krajach w gospodarstwach rodzinnych i farmerskich dąży się do obniżenia kosztów produkcji zwierzęcej. Głównym kierunkiem prac umożliwiających osiągnięcie tego celu jest opracowanie nowych technicznych rozwiązań charakteryzujących się niską energochłonnością i wysoką wydajnością z zachowaniem wysokiej jakości produktu (surowca) przy produkcji pasz. Przykładowo w ostatnich latach w produkcji zwierzęcej pozyskuje się koncentraty o niskich kosztach jednostkowych, a zastosowanie rozdrabniania i gniecenia ziarna umożliwia realizację tego celu związanego z obniżeniem kosztów produkcji pasz. Prowadzone do tej pory badania naukowe i analiza literatury wykazują, że dotychczasowe rozwiązania charakteryzują się dużymi błędami wynikającymi z konstrukcji urządzeń, a także efektem technologicznym uzyskanego rozdrabnianego produktu (ziarna). W pracy przedstawiono kryteria optymalizacji wskaźników technicznych urządzeń rozdrabniających wpływających na jakość produktu.
\end{abstract}

Slowa kluczowe: rozdrabniacze, ziarno, eksperyment, rotor, bijak, nóż rozdrabniacza

Identification data Authors:

Petr Savinykh https://orcid.org/0000-0002-5668-8479

Alexey Yu. Isupov https://orcid.org/0000-0002-3399-5089

Andrey Palichyn https://orcid.org/0000-0001-5901-5678

Ilaya I. Ivanov https://orcid.org/0000-0003-3388-9865

Wacław Romaniuk https://orcid.org/0000-0001-7776-9940

Kinga Borek https://orcid.org/0000-0002-0171-7498 